NBER WORKING PAPER SERIES

INFLATION TARGETING: SHOULD IT BE MODELED AS AN INSTRUMENT RULE OR A TARGETING RULE?

\author{
Lars E.O. Svensson \\ Working Paper 8925 \\ http://www.nber.org/papers/w8925 \\ NATIONAL BUREAU OF ECONOMIC RESEARCH \\ 1050 Massachusetts Avenue \\ Cambridge, MA 02138 \\ May 2002
}

The views expressed herein are those of the author and not necessarily those of the National Bureau of Economic Research.

(C) 2002 by Lars E.O. Svensson. All rights reserved. Short sections of text, not to exceed two paragraphs, may be quoted without explicit permission provided that full credit, including (C) notice, is given to the source. 
Inflation Targeting: Should It Be Modeled as an Instrument Rule or a Targeting Rule?

Lars E.O. Svensson

NBER Working Paper No. 8925

May 2002

JEL No. E42, E52, E58

\begin{abstract}
The paper discusses how current inflation targeting should be modeled, and argues that it is better represented as a commitment to a targeting rule (a rule specifying operational objectives for monetary policy or a condition for the target variables), than as a commitment to a simple instrument rule (like a Taylor rule).
\end{abstract}

Lars E.O. Svensson

Department of Economics

Fisher Hall

Princeton University

Princeton, NJ 08544-1021

and NBER

Tel: 609-258-0329

Fax: 609-258-7573

svensson@princeton.edu

http://www.princeton.edu/ svensson 


\title{
Inflation Targeting: Should It Be Modeled as an Instrument Rule or a Targeting Rule?*
}

\author{
Lars E.O. Svensson \\ Princeton University, CEPR and NBER
}

December 2001

\section{Introduction}

Inflation targeting was introduced in New Zealand in 1990, so by now we have about 10 years of experience. It spread very quickly to an increasing number of countries: Canada 1991, the UK 1992, Sweden, Finland and Australia 1993. The Czech Republic was the first transition economy to introduce inflation targeting, and Brazil was the first developing country to introduce fullfledged inflation targeting. Israel and Chile have gradually developed into inflation targeters. Recent additions in Europe include Switzerland, Norway and Iceland. ${ }^{1}$

Except for research on the beneficial consequences of central-bank independence and low inflation, and academic advice by Charles Goodhart on the incentive structure for the Governor of the Reserve Bank of New Zealand, inflation targeting was introduced in early 1990s without any preceding specific academic research on inflation targeting. The credit for the initial rise of inflation targeting goes mostly to insightful central-bank and finance-department officials rather than academics. Once inflation targeting was introduced in the mid 1990s, though, an increasing number of academics started to do research on the topic, and by now there is large volume of

\footnotetext{
${ }^{*}$ This paper is a shortened version of a presentation at the EEA 2001 Annual Congress, Lausanne, August 2001. I thank Kathleen DeGennaro for secretarial and editorial assistance. Homepage: www.princeton.edu/ $\sim$ svensson/.

${ }^{1}$ However, stating reasons that I find contrived and unconvincing, the Swiss National Bank insists that it is not doing inflation targeting, in spite of it fulfilling the criteria specified below (Baltensperger, Fischer and Jordan, 2001).
} 
accumulated research, and the number of papers and books on inflation targeting is growing fast.

How should we define inflation targeting? I believe it is useful to emphasize three characteristics: (1) There is a numerical inflation target, in the form of either a point target (with or without a tolerance interval) or a target range. This numerical inflation target refers to a specific price index. Achieving the inflation target is the primary objective of monetary policy, although there is room for additional secondary objectives, as we shall see. There is no other nominal anchor, like an exchange-rate target or a money-growth target. (2) The decision-making process can be described as "inflation-forecast targeting," in the sense that the central bank's inflation forecast has a prominent role and the instrument is set such that the inflation forecast conditional in the instrument-setting is consistent with the target. This does not exclude that output and output-gap forecasts also enter in an essential way, as we shall see. (3) There is a high degree (an exceptionally high degree, by historical standards) of transparency and accountability. The central bank is accountable for achieving the inflation target and provides transparent and explicit monetary-policy reports presenting its forecasts and explaining and motivating its policy.

However, these days many countries call themselves inflation targeters without seeming to take the inflation targeting very seriously. Indeed, an institutional commitment to inflation targeting appears essential for inflation targeting to have much meaning. Such an institutional commitment involves (1) a clear (preferably legislated) mandate for a monetary policy directed towards low inflation, (2) central-bank independence ("instrument independence," meaning independence in setting the monetary-policy instrument, in some cases also independence in formulating an operational interpretation of the low-inflation mandate), and (3) accountability of the central bank for achieving the mandate.

By now a large amount of research has been done on inflation targeting and related research topics. There has been work on institutions and political economics, for instance on governance, independence, delegation, accountability, decision-making in committees, and the role of transparency for incentives. There has been work on many aspects of the transmission mechanism, including aggregate supply/Phillips curves, aggregate demand/IS curves, the credit channel and the financial accelerator, the impact of asset prices, the term structure of interest rates, the role of money, and the fiscal theory of the price level. There has been work on monetary-policy objectives, including the relation between inflation and economic growth, targeting inflation 
versus alternatives (the price level, nominal GDP, money growth, exchange rates, etc.), flexible versus strict inflation targeting (to what extent inflation targeting includes concerns about the real economy, the output gap, interest rates, and the exchange rate), the relation between social welfare (utility of the representative consumer) and the frequently used quadratic loss functions representing inflation targeting, and the role of interest-rate stabilization/smoothing. A good part of the research has been on monetary-policy rules, including whether commitment or discretion is the realistic assumption, properties of simple instrument rules, especially Taylor-type rules, and the relation between instrument rules and targeting rules (to be defined). There has been work on monetary policy under uncertainty, for instance, on partial information about state of the world, certainty-equivalence, optimal estimation and control; on model uncertainty, Brainard-type multiplicative uncertainty, robust control versus Bayesian control; and on whether uncertainty implies more cautious or more aggressive policy. There has been work on the role of transparency and credibility for successful inflation targeting. A research area of enormous practical importance, given the deteriorating economic situation in Japan, concerns avoiding and escaping from liquidity traps and deflation, and handling the zero bound on nominal interest rates. Much recent work has focused explicitly on inflation targeting in open economies, including the choice of the optimal target index the role of the exchange-rate. The pros and cons of inflation targeting in developing economies and transition economies is an increasingly important research area (Amato and Gerlach, 2002).

There is no way I can cover this massive amount of work in a short paper. Instead I will focus on one controversial issue, where I have done some research of my own (especially in Svensson, 2001b), namely how to model inflation targeting: more specifically, what the policy rule is, and whether this policy rule is best seen as an instrument rule or a targeting rule. ${ }^{2}$

\section{How to model inflation targeting?}

There is by now widespread agreement among central bankers and academics that inflation targeting in practice is "flexible" inflation targeting (see, for instance, several contributions in Federal Reserve Bank of Kansas City, 1996 and 1999): The objective is to stabilize inflation around the inflation target, but also to put some weight on stabilizing the output gap, the difference between actual output and the "natural" output level, potential output (the level of

\footnotetext{
${ }^{2}$ My presentation at the EEA 2001 Annual Congress also covered the the issues of commitment versus discretion in inflation targeting, the relation between inflation targeting and welfare-optimizing policy, and the zero bound for interest rates and liquidity traps. Because of space constraints, these issues are not discussed here.
} 
output that would result with flexible prices). Such an objective can be described by a quadratic intertemporal loss function in period $t$,

$$
\mathcal{L}_{t}=(1-\delta) \mathrm{E}_{t} \sum_{\tau=0}^{\infty} \delta^{\tau}\left[\left(\pi_{t+\tau}-\pi^{*}\right)^{2}+\lambda x_{t+\tau}^{2}\right],
$$

where $\delta(0<\delta<1)$ is a discount factor, $\mathrm{E}_{t}$ denotes expectations conditional on information available in period $t, \pi_{t}$ and $x_{t}$ denote inflation and the output gap in period $t$, respectively, $\pi^{*}$ is the inflation target, and $\lambda>0$ is the relative weight on output-gap stabilization. Thus, inflation and the output gap are the "target variables," that is, the variables that enter the loss function. The corresponding "target levels" are $\pi^{*}$ and zero. The zero target level for the output gap corresponds to an output target equal to potential output. There is general agreement that inflation-targeting central banks do normally not have overambitious output targets, that is, exceeding potential output. Thus, discretionary optimization does not result in average inflation bias, counter to the case in the standard Kydland-Prescott-Barro-Gordon setup. Since the inflation target is subject to choice but not the output target, there is an asymmetry between the inflation and output target, consistent with the inflation target being the "primary objective." 3

Regarding the two parameters, $\delta$ and $\lambda$, the discount factor is for all practical purposes likely to very close to one, especially when a quarterly model is used. Interestingly, when the discount factor approaches one, the limit of the intertemporal loss function is the weighted sum of the unconditional variances of inflation and the output gap,

$$
\lim _{\delta \rightarrow 1} \mathcal{L}_{t}=\operatorname{Var}\left[\pi_{t}\right]+\lambda \operatorname{Var}\left[x_{t}\right]
$$

(when the unconditional mean of inflation and the output gap equal the inflation target and zero, respectively; $\mathrm{E}\left[\pi_{t}\right]=\pi^{*}$ and $\left.\mathrm{E}\left[x_{t}\right]=0\right)$. As mentioned, flexible inflation targeting corresponds to $\lambda>0$. "Strict" inflation targeting would be the unrealistic case of $\lambda=0$.

\subsection{Commitment to a simple instrument rule}

How do and should inflation-targeting central banks achieve the inflation target and minimize the loss function? Most of the literature discusses this in terms of a commitment to a simple reaction function, a simple "instrument rule," where the central bank mechanically sets its instrument

\footnotetext{
${ }^{3}$ An interesting and important research area, discussed in my presentation at the EEA 2001 Annual Congress, concerns to what extent inflation targeting as represented by (2.1) corresponds to maximizing the welfare of the representative consumer. Another research area is to what extent a quadratic loss function is sufficient, or if higher-order terms corresponding to asymmetric preferences are needed.
} 
rate (usually a short interest rate like a one- or two-week repurchase rate), $i_{t}$, as a given simple function of a small subset of the information available to the central bank. Although several different simple instrument rules have been discussed since the 1970s, the best known and most discussed is the Taylor (1993) rule, a frequent variant of which can be written

$$
i_{t}=\left(1-f_{i}\right)\left[\bar{r}+\pi_{t}+f_{\pi}\left(\pi_{t}-\pi^{*}\right)+f_{x} x_{t}\right]+f_{i} i_{t-1},
$$

where the response coefficients $f_{\pi}, f_{x}$ and $f_{i}$ fulfill $f_{\pi}>0, f_{x}>0$ and $0 \leq f_{i} \leq 1$ (although cases with $f_{i}>1$ have also been discussed) and $\bar{r}$ is the average real interest rate. A large volume of research, for instance in Taylor (1999), has examined the properties of (2.3) and its variants in different models, with respect to determinacy of equilibria, performance measured by (2.2), robustness to different models, etc. Several papers have also estimated empirical reaction functions of this type.

The advantages of a simple instrument rule like (2.3) are: (1) The rule can easily be verified by outside observers and a commitment to the rule would therefore be technically feasible. (2) Variants of the Taylor rule have been found to be relatively robust to different models, in the sense that they perform reasonably well (in terms of (2.2)) in simulations with different models and rarely result in very bad outcomes (although these simulations have disregarded the important role of central-bank "judgment," to be discussed below).

The disadvantages are: (1) The rule will not result in an optimal outcome, for several reasons. For instance, it responds only to a small subset of the information about the economy available to the central bank, and it only imperfectly allows for "history dependence." 4 (2) More specifically, because of the simplicity of the rule, there will be many situations when good judgment calls for deviations from the rule. Indeed, Taylor (1993) to a large extent discusses sensible discretionary departures from the rule. But then the rule is incomplete, since it provides no rule for departures from the rule. (3) In spite of all the research and discussion of the Taylor rule, no central bank has made a commitment to follow it. Instead of mechanical instrument-rate decisions, inflation-targeting central banks have set up very elaborate decision-making processes, where huge amounts of information are collected and processed, and conditional forecasts of inflation and output or the output-gap are constructed and contemplated, before an instrument-rate decision is made (Brash, 2001, and Svensson, 2001a). (4) Empirical estimates of Taylor-type reaction functions show that they at most explain $2 / 3$ of the empirical instrument-rate changes

\footnotetext{
${ }^{4}$ Optimal instrument rules in forward-looking models include responses to lagged shocks, "history dependence" in the terminology of Woodford (1999) and Svensson and Woodford (1999).
} 
(Judd and Rudebusch, 1998). Thus, central banks in practice deviate substantially from such a reaction function. Furthermore, a good empirical fit would still be consistent with the reaction function being the endogenous reduced-form outcome of a complex central-bank decision process rather than a commitment that is the beginning and the end of the process.

\subsection{Commitment to a targeting rule}

I find a commitment to a simple instrument rule unsuitable both as description of and prescription for inflation targeting. Instead, I believe inflation targeting is better described and prescribed as a commitment to a "targeting rule." 5 I find it practical to distinguish between "general" and "specific" targeting rules. A general targeting rule specifies the objectives for monetary policy in an operational way, that is, specifies an operational loss function. A commitment to a general targeting rule is hence a commitment to minimize such a loss function. Such a commitment is often taken as given by researchers modeling optimal policy, for instance in the Kydland-Prescott-Barro-Gordon-Rogoff tradition. However, in practical monetary policy, making the objectives operational and explicit, is a large step compared to previous ad hoc policies. Getting the objectives straight and creating an institutional commitment to those objectives are crucial contributions of inflation targeting.

A specific targeting rule is a commitment to set the instrument rate so as to achieve a specific target criterion for the target variables. The Bank of England and Sweden's Riksbank have formulated a simple specific targeting rule to guide policy, which can be expressed as "set interest-rates so the inflation forecast about two years ahead is on target" (Goodhart, 2001, and Heikensten, 1999). Although this specific targeting rule is both simple and operational, it is not necessarily optimal. An optimal specific targeting rule expresses the equality of the marginal rates of transformation and substitution between the target variables in an operational way.

As an example (from Svensson, 2001b, where the details are explained), consider a variant of the popular New Keynesian model, where inflation and the output gap are predetermined one period (a small concession to realism relative to the standard variant when both inflation and the output gap are treated as forward-looking variables, jump variables) and, in particular, "judgment" matters. The aggregate-supply/Phillips curve is

$$
\pi_{t+1}=\pi_{t+2 \mid t}+\alpha_{x} x_{t+1 \mid t}+\alpha_{z} z_{t+1}
$$

\footnotetext{
${ }^{5}$ Target(ing) rules have previously been discussed by Sims (1980), Rogoff (1985), Walsh (1998), Svensson (1997, 1999, 2001b), Rudebusch and Svensson (1999), Cecchetti (1998, 2000), Clarida, Gali and Gertler (1999) and Svensson and Woodford (1999).
} 
where $\pi_{t+2 \mid t}$ denotes expectations in period $t$ of inflation in period $t+2$, etc., $\alpha_{x}$ is a positive constant, $\alpha_{z}$ is a row vector, and $z_{t+1}$ is a column vector (of the same dimension), the "deviation", to be explained below. Thus, inflation in period $t+1$ is determined by expectations in period $t$ of inflation in period $t+2$ and of the output gap in period $t+1$ and by the deviation in period $t+1$. The aggregate-demand/IS curve is

$$
x_{t+1}=x_{t+2 \mid t}-\beta_{x}\left(i_{t+1 \mid t}-\pi_{t+2 \mid t}\right)+\beta_{z} z_{t+1},
$$

where $\beta_{x}$ is a positive constant, $i_{t+1 \mid t}$ is the expectation in period $t$ of the nominal interest rate in period $t+1$ and $\beta_{z}$ is a row vector. Thus, the output gap in period $t+1$ is determined by expectations in period $t$ of the output gap in period $t+2$ and of the real interest rate in period $t+1$ and by the deviation in period $t+1$.

The deviation represents the difference between the true model and this simplified New Keynesian model and includes all other determinants of inflation and the output gap. For simplicity it is treated as an exogenous variable. The central bank's "judgment," $z^{t} \equiv\left\{z_{t+\tau, t}\right\}_{\tau=0}^{\infty}$, is the central bank's best forecast of the deviation. This is a way to represent the importance and inevitability of judgment in monetary policy. Conditional on the central bank's judgment, the bank's forecasting model in period $t$ is then given by

$$
\begin{aligned}
\pi_{t+\tau, t} & =\pi_{t+\tau+1, t}+\alpha_{x} x_{t+\tau, t}+\alpha_{z} z_{t+\tau, t} \\
x_{t+\tau, t} & =x_{t+\tau+1, t}-\beta_{x}\left(i_{t+\tau, t}-\pi_{t+\tau+1, t}\right)+\beta_{z} z_{t+\tau, t},
\end{aligned}
$$

for forecast horizons $\tau \geq 1$ (where $\pi_{t+\tau, t}$ refers to the central bank's $\tau$-period-ahead forecast of inflation in period $t$, etc.).

The optimal specific targeting rule for the loss function (2.1) and the model (2.6) and (2.7) can then be found by finding the marginal rate of transformation (MRT) and substitution (MRS) between (the forecasts of) the target variables (inflation and the output gap), and setting these equal. A marginal increase in inflation two periods ahead only, $d \pi_{t+2, t}>0, d \pi_{t+j, t}=0$, $j \neq 2$, by the aggregate-supply relation (2.6) requires a fall in the output gap one period ahead, $d x_{t+1, t}=-d \pi_{t+2, t} / \alpha_{x}<0$, and an equal increase in the output gap two periods ahead, $d x_{t+2, t}=-d x_{t+1, t}>0$. We can then define the marginal rate of transformation of the linear combination $\tilde{x}_{t+1, t} \equiv\left(x_{t+1, t}, x_{t+2, t}\right) \equiv(1,-1) x_{t+1, t}$ into $\pi_{t+2, t}, \operatorname{MRT}\left(\pi_{t+2, t}, \tilde{x}_{t+1, t}\right)$, which will equal

$$
\left.\operatorname{MRT}\left(\pi_{t+2, t}, \tilde{x}_{t+1, t}\right) \equiv \frac{d \pi_{t+2, t}}{d x_{t+1, t}}\right|_{d x_{t+2, t}=-d x_{t+1, t}}=-\alpha_{x}
$$


From the loss function (2.1) (when the forecasts enter as arguments) follows that the marginal rate of substitution of $\pi_{t+2, t}$ for $x_{t+j, t}$ is given by $\operatorname{MRS}\left(\pi_{t+2, t}, x_{t+j, t}\right) \equiv d \pi_{t+2, t} /\left.d x_{t+j, t}\right|_{d \mathcal{L}_{t}=0}=$ $-\lambda x_{t+j, t} /\left(\pi_{t+2, t}-\pi^{*}\right)$ (in the limit when $\delta \rightarrow 1$, for simplicity). From this it is easy to show that the marginal rate of substitution of $\pi_{t+2, t}$ for the above linear combination $\tilde{x}_{t+1, t}$, $\operatorname{MRS}\left(\pi_{t+2, t}, \tilde{x}_{t+1, t}\right)$, will be given by

$$
\left.\operatorname{MRS}\left(\pi_{t+2, t}, \tilde{x}_{t+1, t}\right) \equiv \frac{d \pi_{t+2, t}}{d x_{t+1, t}}\right|_{d \mathcal{L}_{t}=0, d x_{t+2, t}=-d x_{t+1, t}}=\frac{\lambda\left(x_{t+2, t}-x_{t+1, t}\right)}{\pi_{t+2, t}-\pi^{*}} .
$$

Redoing this for $\pi_{t+\tau, t}$ for all $\tau \geq 1$ and setting the marginal rates of transformation equal to the marginal rates of substitution leads to the optimal specific targeting rule,

$$
\pi_{t+\tau, t}-\pi^{*}=-\frac{\lambda}{\alpha_{x}}\left(x_{t+\tau, t}-x_{t+\tau-1, t}\right)
$$

where $x_{t, t}$ for $\tau=1$ is understood to be $x_{t, t-1}$, the one-period-ahead forecast of the output gap in period $t-1$. Thus, the optimal targeting rule in this example can be expressed as "find an instrument-rate path so the inflation-gap forecast is $-\lambda / \alpha_{x}$ times the change in the output-gap forecast." 6

In this example, optimal "inflation-forecast targeting" can then be described as follows: (1) Conditional on the judgment $z^{t} \equiv\left\{z_{t+\tau, t}\right\}_{\tau=0}^{\infty}$, find inflation and output gap forecasts, $\pi^{t} \equiv$ $\left\{\pi_{t+\tau, t}\right\}_{\tau=1}^{\infty}$ and $x^{t} \equiv\left\{x_{t+\tau, t}\right\}_{\tau=1}^{\infty}$, that fulfill the specific targeting rule (2.8) and the aggregatesupply relation (2.6). (2) Conditional on the judgment and these forecasts, find the instrumentrate forecast, $i^{t} \equiv\left\{i_{t+\tau, t}\right\}_{\tau=0}^{\infty}$, that fulfills the aggregate-demand relation (2.7). (3) Announce these forecasts and set the instrument-rate accordingly. This results in the optimal instrumentrate setting, conditional on the judgment, $z^{t}$, without having to specify the optimal reaction function. As is shown in Svensson (2001b), even for this relatively simple model, the optimal reaction function is overwhelmingly complex, especially since it must specify how to respond optimally to judgment, making verifiability and commitment directly to the optimal reaction function completely unrealistic.

The advantages of an optimal specific targeting rule like (2.8) are: (1) With published forecasts of the target variables, it is possible to verify whether the target rule is followed, since the targeting rule is relatively simple. Then commitment to the targeting rule is possible. (2) The optimal specific targeting rule results in the fully optimal outcome, corresponding to

\footnotetext{
${ }^{6}$ As is explained in Svensson (2001b), (2.8) also applies for $\tau=1$, when $x_{t, t}$ is interpreted to be $x_{t, t-1}$. Formulating the targeting rule this way leads to "optimality in a time-less perspective," corresponding to a situation of commitment to optimal policy far in the past, as discussed in Woodford (1999) and Svensson and Woodford (1999).
} 
commitment in a timeless perspective. (3) The specific targeting rule is relatively robust, in that it only depends on the marginal tradeoffs between the target variables, that is, the derivatives of the loss function and the aggregate-supply relation with respect to the target variables. (4) The specific targeting rule is independent of judgment, in the sense of judgment not entering the targeting rule explicitly, but still allows the incorporation of judgment, since judgment enters in the forecasts.

A potential disadvantage, however, is that a specific targeting rule, in order to be optimal, depends on the precise marginal rate of transformation, the dynamic tradeoff, between the target variables. Therefore, it is not robust to different models of the aggregate-supply relation (Svensson 2001b compares the optimal specific targeting rule for a backward-looking and a forward-looking model). Thus, it is clearly less robust than a commitment to a general targeting rule (but still much more robust than a commitment to the optimal instrument rule).

Specific targeting rules are the Euler conditions corresponding to optimizing monetary policy. I believe it is better to describe and prescribe inflation targeting as goal-directed, optimizing policy than as following a mechanical instrument rule. Monetary policy by the world's more advanced central banks these days is at least as optimizing and forward-looking as the behavior of the most rational private agents. I find it strange that a large part of the literature on monetary policy still prefers to represent central-bank behavior with the help of mechanical instrument rules. The literature long ago ceased representing optimizing households and firms as following mechanical consumption and investment functions, and instead represents their behavior by Euler conditions, optimal first-order conditions. The concept of general and specific targeting rules is designed to provide a discussion of monetary policy rules that is fully consistent with the optimizing and forward-looking nature of modern monetary policy. From this point of view, general targeting rules essentially specify operational objectives for monetary policy, and specific targeting rules essentially specify operational Euler conditions for monetary policy. In particular, an optimal targeting rule expresses the equality of the marginal rates of transformation and the marginal rates of substitution between the target variables in an operational way. I hope there will be more research along these lines in the future.

\section{Conclusions}

Inflation targeting is an active and lively research area. It is also an area where academic research matters for practical policy. Inflation-targeting central banks are eager to apply new research 
findings, and the distance between research and practice is very short. There is considerable cooperation between academic researchers and researcher at central banks -indeed, some of the best work in the area has been done at some central banks. Many unresolved issues remain, though. The limited space here has only allowed me to touch on one such issue.

\section{References}

Amato, Jeffery D., and Stefan Gerlach (2002), "Inflation Targeting in Emerging Market and Transition Economies: Lessons after a Decade," European Economic Review 46, 000-000.

Baltensperger, Ernst, Andreas M. Fischer and Thomas J. Jordan (2001), "Abstaining from Inflation Targets: Understanding SNB Rhetoric in the Inflation Targeting Debate," working paper, Swiss National Bank.

Brash, Donald T. (2001), "Making Monetary Policy: A Look behind the Curtains," speech in Christchurch, New Zealand, January 26, 2001, Reserve Bank of New Zealand.

Cecchetti, Stephen G. (1998), "Central Bank Policy Rules: Conceptual Issues and Practical Considerations," in Helmut Wagner, ed., Current Issues in Monetary Economics, PhysicaVerlag, Heidelberg, 121-140.

Cecchetti, Stephen G. (2000), "Making Monetary Policy: Objectives and Rules," Oxford Review of Economic Policy 16(4), 43-59.

Clarida, Richard, Jordi Galí and Mark Gertler (1999), "The Science of Monetary Policy: A New Keynesian Perspective," Journal of Economic Literature 37, 1661-1707.

Federal Reserve Bank of Kansas City (1996), Achieving Price Stability, Federal Reserve Bank of Kansas City, Kansas City.

Federal Reserve Bank of Kansas City (1999), New Challenges for Monetary Policy, Federal Reserve Bank of Kansas City, Kansas City.

Goodhart, Charles A.E. (2001), "Monetary Transmission Lags and the Formulation of the Policy Decision on Interest Rates," Federal Reserve Bank of St. Louis Review 83, July/August 2001, 165-181. 
Heikensten, Lars (1999), "The Riksbank's Inflation Target-Clarification and Evaluation," Sveriges Riksbank Quarterly Review 1/1999, 5-17.

Judd, John P., and Glenn D. Rudebusch (1998), "Taylor's Rule and the Fed: 1970-1997," Federal Reserve Bank of San Francisco Economic Review 1998(3), 3-16.

Rogoff, Kenneth (1985), "The Optimal Degree of Commitment to an Intermediate Monetary Target," Quarterly Journal of Economics 100, 1169-1190.

Rudebusch, Glenn D., and Lars E.O. Svensson (1999), "Policy Rules for Inflation Targeting," in Taylor (1999), 203-246.

Sims, Christopher A. (1980), "Macroeconomics and Reality," Econometrica 48, 1-48.

Svensson, Lars E.O. (1997), "Inflation Forecast Targeting: Implementing and Monitoring Inflation Targets," European Economic Review 41, 1111-1146.

Svensson, Lars E.O. (1999), "Inflation Targeting as a Monetary Policy Rule," Journal of Monetary Economics 43, 607-654.

Svensson, Lars E.O. (2001a), "Independent Review of the Operation of Monetary Policy in New Zealand: Report to the Minister of Finance," www.princeton.edu/ svensson/.

Svensson, Lars E.O. (2001b), "What is Wrong with Taylor Rules? Using Judgment in Monetary Policy through Targeting Rules," working paper, Princeton University.

Svensson, Lars E.O., and Michael Woodford (1999), "Implementing Optimal Policy through Inflation-Forecast Targeting," working paper, Princeton University.

Taylor, John B. (1993), "Discretion versus Policy Rules in Practice," Carnegie-Rochester Conference Series on Public Policy 39, 195-214.

Taylor, John B., ed. (1999), Monetary Policy Rules, Chicago University Press, Chicago.

Walsh, Carl E. (1998), Monetary Theory and Policy, MIT Press, Cambridge, MA.

Woodford, Michael (1999), "Commentary: How Should Monetary Policy Be Conducted in an Era of Price Stability?" in Federal Reserve Bank of Kansas City (1999), 277-316. 